\title{
Strategies to Teach Elementary School Students the Principles of Blockchain Technology by Implementing Gamification
}

\author{
Eunsun Choi, Major in Computer Education, Faculty of Science Education, Graduate School, Jeju National \\ University, choi910624@jejunu.ac.kr \\ Yujin Jung, Department of Convergence Information Security, Graduate School, Jeju National University, \\ yujinjung@jejunu.ac.kr \\ *Namje Park, Department of Computer Education, Teachers College, Jeju National University, 61 Iljudong- \\ ro, Jeju-si, Jeju Special Self-Governing Province, 63294, Korea, namjepark@jejunu.ac.kr \\ *Corresponding Author
}

\begin{abstract}
Blockchain is a distributed data storage technology. Recently, hacking incidents have continued. And blockchain is the one of the key ideas in the era of the Fourth Industrial Revolution. In this paper, we propose a way of incorporating games into education so that students can enjoy learning the core skills of the blockchain. In particular, the game was organized with the aim of understanding blockchain principles. It is also verified with students in the actual educational field to investigate learners' satisfaction with the educational plan and confirm learner's understanding before and after training. The effectiveness of this paper's gamification education is demonstrated by confirming learners' satisfaction and understanding. Blockchain is a technology devised by Satoshi Nakamoto in 2007 and is a relatively recently established technology. For elementary school students, the concept of blockchain can be unfamiliar and complicated. These complex and challenging skills can be effectively taught to elementary school students through game-based education. It can be seen that the educational method proposed in this paper is an effective way to improve students' core competencies in the 21st century, such as knowledge-information processing capability, communication capability, and community capability. With the importance of information security emerging day by day, the blockchain is emerging as an effective countermeasure to reduce the damage caused by information leakage. Teaching young learners the principles of this technology can inspire adaptability for promising future. It can also be applied to gradually reduce the damage caused by information leakage by alerting them to information security.
\end{abstract}

Keywords: Gamification, blockchain Technology(BCT), computational thinking, computational thinki ng, Information and Communications Technologies education

Received: 07.12.2020 Accepted: 10.01.2021 $\quad$ Published: 03.02.2021

\section{INTRODUCTION}

The emphasis accordingly highlights the need for making computing skills more easily approachable in elementary school education. That said, specialized computing skills could visibly reduce students' participation, leading to a decrease in their concentration, thus possibly impacting the quality of classes. Of note, reviews of statistical materials regarding classroom-based teaching/learning in the past show that approximately $35 \%$ of the South Korean students reported that they enjoyed their classes, falling behind France's corresponding responses (55\%) and the U.K. (48\%). The exploitation of gamification, where game-like elements are combined to conventional classroom approaches, is considered to be a positive way of encouraging students to more spontaneously take an interest and helping them pay more attention to their classes. This paper aims at increasing students' classroom participation by implementing game-like elements to the blockchain, and at inspiring students to spontaneously take an interest in their learning by helping to increase their satisfaction with classes. Additionally, the study aims to propose a strategy for nurturing students' understanding of the principle of blockchain and their skills to analyze elements from varied perspectives[1].

\section{Related research}

\section{The concept of gamification}

The term 'gamification' was coined from the word 'game' and was first used by Nick Pelling in 2002. Gamification means combining game-based mechanisms, aesthetic elements, ways of thinking, etc. that let one immersed, that motivate his/her actions, facilitate learning, and help solve problems to non-game-like 
contexts. In the previous, 'game' can be defined as an activity that includes skills, knowledge, and opportunities for solving problems under specific rules and making efforts to win. Table 1 lists the characteristics of games, e.g., providing clear sets of rules and purposes and clarifying the conditions for winning and for terminating the game, which can provide users with a sense of purpose and help increase the level of interest in them[2].

Table 1. Characteristics of game

\begin{tabular}{|c|c|}
\hline Researcher & Characteristics \\
\hline Caillois(2001) & $\begin{array}{l}\text { - It should be fun. } \\
\text { There are limitations in terms of time and space. } \\
\text { - There is uncertainty in the play result. } \\
\text { - It is unproductive activity. } \\
\text { - There are different rules than everyday life. } \\
\text { - Provide fictional stories. }\end{array}$ \\
\hline Schell(2008) & $\begin{array}{l}\text { The game starts voluntarily. } \\
\text { The game has a purpose. } \\
\text { - There is competition and confrontation in game. } \\
\text { - There are rules in the game. } \\
\text { - There is a win and a loss in the game. } \\
\text { - The game is interactive. } \\
\text { - The game provides a challenge. } \\
\text { - Game is worth to exist only inside. } \\
\text { - The game makes the player participate. }\end{array}$ \\
\hline
\end{tabular}

\subsection{Blockchain education}

As the blockchain has received social attention, education related to blockchain technology is also slowly starting. However, due to blockchain technology's essential characteristics, it is challenging to educate ordinary people or young students without related knowledge. Besides, research on education related to the concept of blockchain technology is still only at the beginning. By the way, some studies introduce useful concepts when teaching blockchain technology to these learners. Table 2 suggests that teaching the concepts of blockchain data structure, security, and bitcoin to elementary school students and the general public is an easy way to explain the blockchain's systematic structure.

There is also a way to effectively teach newcomers how to mine the blockchain through a serious game. Users playing the game can find fun by competing against other users with the same skill level. At the end of the game, it shows his results in real-time so that the user can find a better way to mine blocks[3].

Table 2. Concepts and educational steps for blockchain education

\begin{tabular}{l|l|l}
\hline Target & Concepts & Educational Steps \\
\hline \hline \multirow{2}{*}{$\begin{array}{l}\text { Blockchain } \\
\text { Newcomers }\end{array}$} & $\begin{array}{l}\text { Blockchain and Distributed Ledger } \\
\text { Technology(DLT) }\end{array}$ & - \\
\hline & & - Encryption of Data \\
& Security of Blockchain & $\begin{array}{l}\text { Modification Prevention } \\
\cdot \text { Insertion new blocks }\end{array}$ \\
& & Verification of Data \\
\hline
\end{tabular}




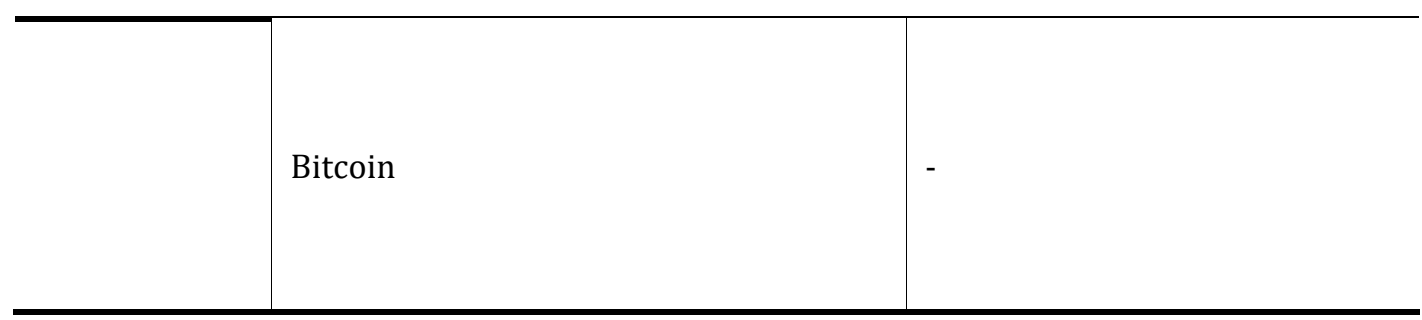

Model of teaching and learning BCT principles

\subsection{Instructional design model}

Gamification has been implemented in a variety of classroom subjects and has been studied as well. Notably, several gamification studies have applied the instructional design model proposed by Dick and Carey to proceed with their classroom implementation research. This model has six steps: Determination of learning objectives, selection of game materials, design of the game structure, design of game materials, creation of game rules, inspection, and correction. The instructional model proceeds in steps as follows $[4,5]$ :

[Step 1] Set educational goals

Define new information, functions, and goals/objectives that the students must master until the class ends.

[Step 2] Analyze tasks

Analyze the goals/objectives for distinguishing learning scopes and achievable behavioral steps, and divide functions for achieving step-wise goals.

[Step 3] Analyze entry behavior and learners' characteristics

Analyze learning goals/objectives and learners' characteristics/environments.

[Step 4] State implementation goals

Describe learning stage-specific intellectual functions, motor functions, linguistic information, and attitudes of learners.

[Step 5] Develop a criterion-referenced test questionnaire

Develop tools for assessing/evaluating learners' achievements.

[Step 6] Develop learning/teaching strategies

Develop the design principle and elements for gamification.

[Step 7] Develop and select classroom materials

Develop the gamification design principle and elements.

[Step 8] Design and implement formative evaluation

Analyze and review classroom designs from holistic points of view.

[Step 9] Revise programs

Carry out the necessary revisions in each step.

[Step 10] Conduct overall evaluation

- Design research studies and collect data.

- Propose goals/objectives and rules for learners.

- Present storytelling (narrative) related to real-world practices.

- Propose tasks that are ethical and achievable. 


\subsection{Process for developing educational blockchain game}

This game is designed based on the game development's general steps by Livingstone \& Stoll. They proposed six steps: deciding learning goals, selecting game materials, designing game structures, designing game materials, writing game rules, and testing and revising. This section introduces the procedures for developing blockchain games[6,7].

[Step 1] Determine learning goals

Set understanding the principles of blockchain' as the learning goal.

[Step 2] Select game materials

For game materials, design a card game where the cards are laid overturned, and the opponents' cards are taken when the player correctly guesses them.

[Step 3] Design game structures

In the blockchain, each user stores his/her transaction information. As such, modifying the normal transactions would need to alter the transaction details of at least $51 \%$ of the system's users. Applying this rule, design a game structure so that it is more challenging for the players to guess out multiple cards with a single trial than to guess out a single card and claim it.

[Step 4] Design game materials

To play the game, the designers are required to produce two materials: a manual that explicitly describes how the game is played; and the deck of cards to be played. Figure 1 is a card sample for the game.

[Step 5] Write game rules

Write the rules for the game as follows:

- The back of a card comes in a total of three colors.

- Overturn six red cards to show their back.

- When it is one player turns to play, say out loud the amount of money presumably written on whose opponent's card and turn the card over. With a correct guess, he/she claims the card as his/hers. If not, overturn the card and place it where it was before.

- When consuming all six of the blue cards, overturn a gold card.

- Correctly guessing the amount of money written on the back of the opponents' cards will allow the counterpart to claim the cards. However, depending on the color of their back, the user claims the cards in different manners.

- With red cards, if the user correctly guesses the amount written on a card, he/she can claim the card right away.

- With blue cards, the user can claim the cards only if he/she has overturned two cards with the same amount written on their back.

- With gold cards, three overturned cards with the same amount written on their back will allow he/she to take them.

[Step 6] Test and revise

Give the designed game a try, identify problems during the trial, and make the necessary revisions to make the game a more articulate model. 


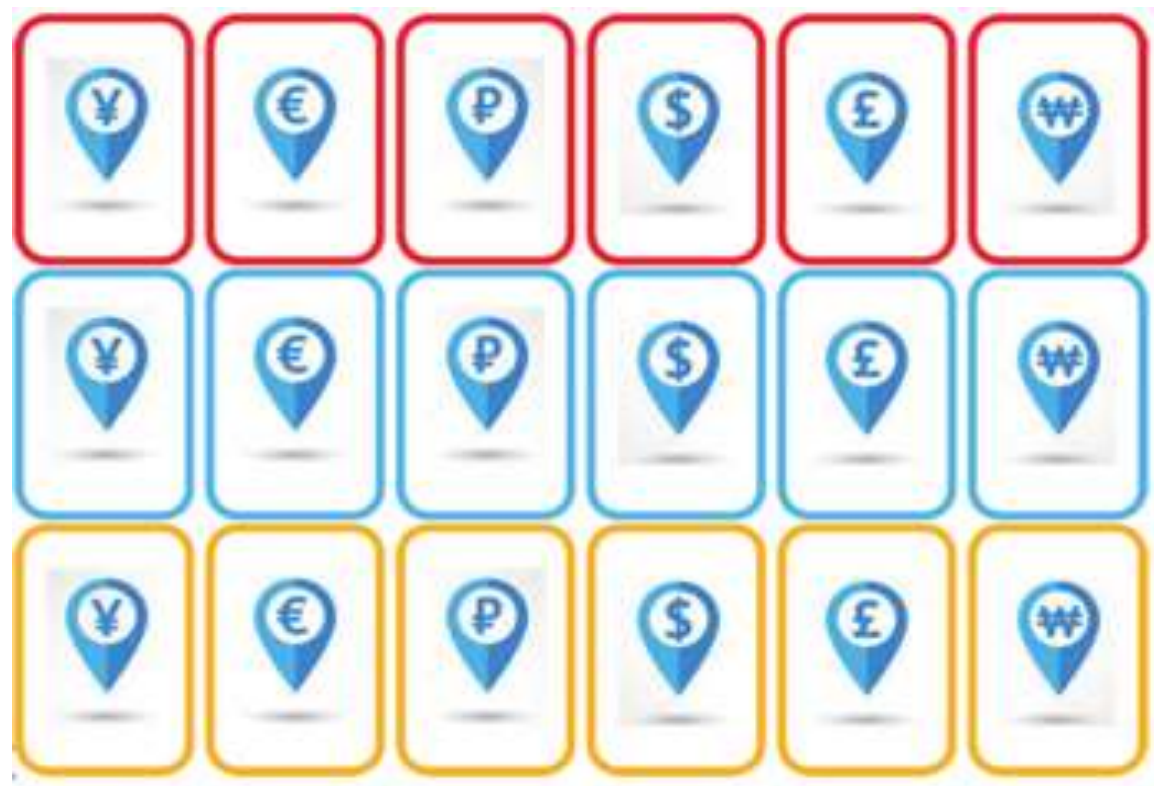

Fig 1. Game cards

\section{Result discussions}

Figure 2 shows the field of pilot application of the proposed blockchain game to elementary students. And also, figure 3 shows the study material used in the class.

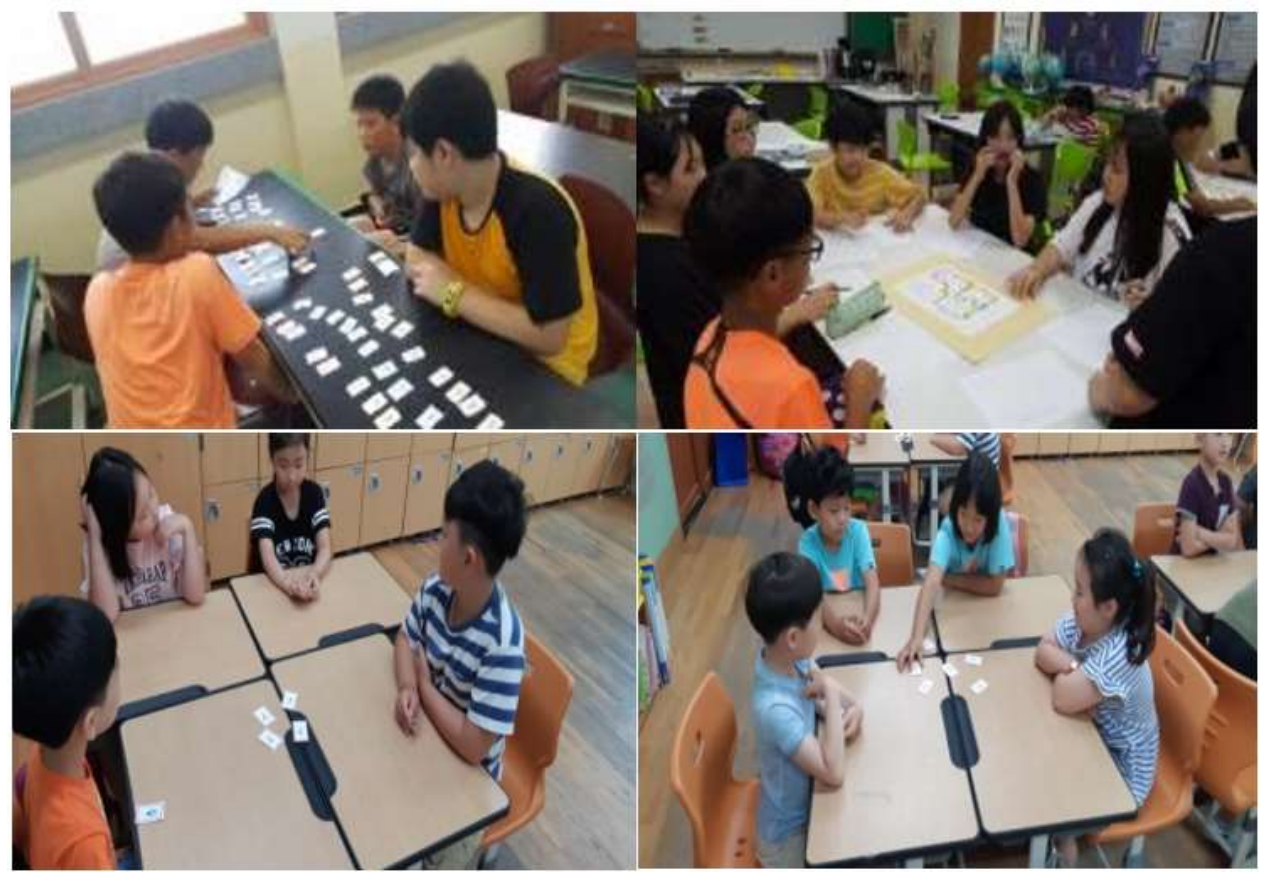

Fig 2. Students playing the blockchain game 

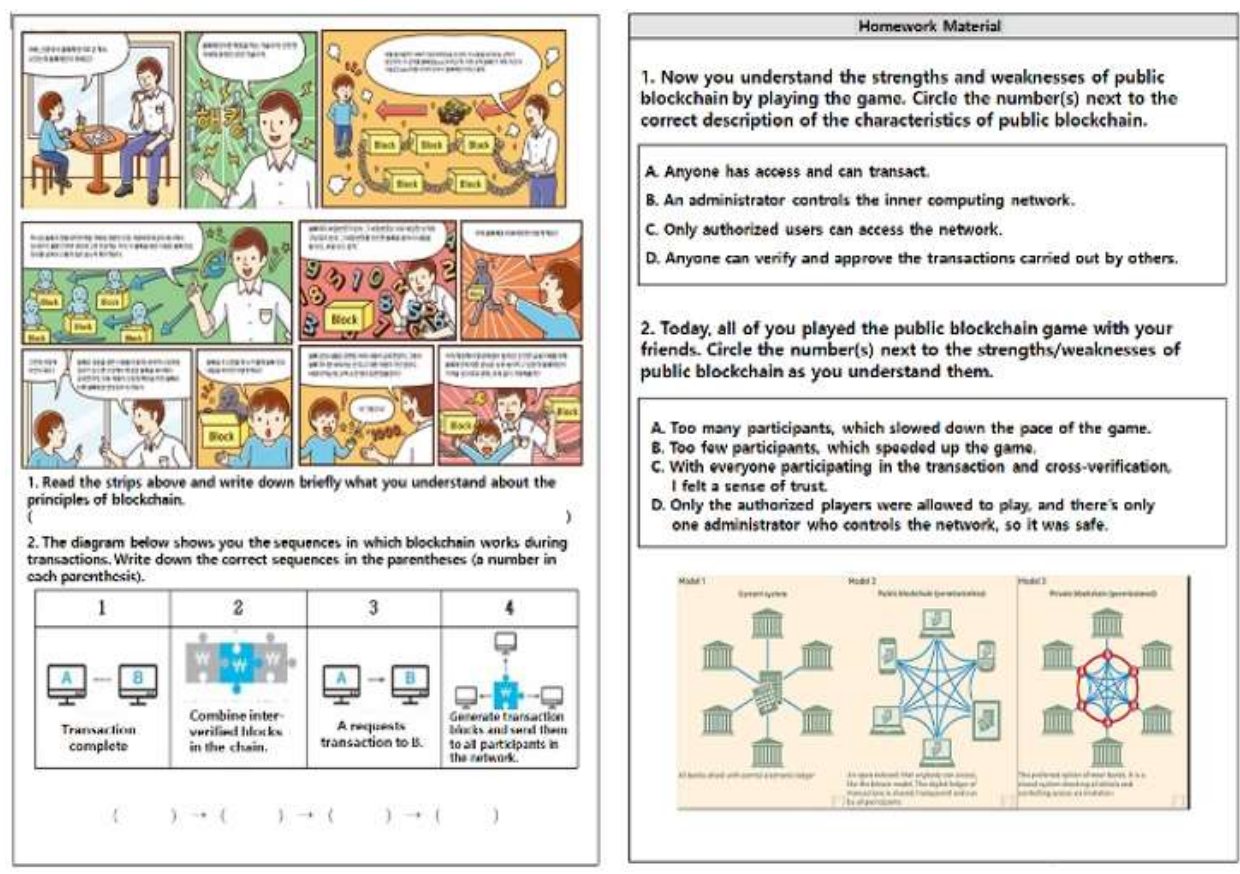

Fig 3. Study materials

To verify the effectiveness of the developed class materials and class designs, the present researcher targeted Elementary Schools A and B in Jeju Island, leading the classes at these schools, respectively. Preand post-learning questionnaires were given to the students on the subject of blockchain principles to verify the changes in their understanding. From the two elementary schools in Jeju Island, 69 students were recruited (29 and 40, respectively). Additionally, questionnaire surveys were given to each student (pre- \& post-implementation surveys) to determine the level of satisfaction experienced by the participants regarding the goal of learning and their understanding of the BCT principles before and after the implementing gamification education. A survey questionnaire about the students' understanding of their subject matter was given by using 40 questions, each with a five-point rating scale. According to the survey results(Table 3), Elementary School A responded with a mean score of 3.80 in class satisfaction and 3.75 in subject understanding. The corresponding numbers reported from Elementary School B were 3.77 and 4.15, respectively[8].

Table 3. Satisfaction and Intelligibility

\begin{tabular}{l|l|l|l}
\hline & \multirow{2}{*}{ Satisfaction } & Intelligibility & \\
\cline { 3 - 4 } & & Before & After \\
\hline \hline $\mathrm{A}$ & 3.795833 & 1.291667 & 3.745833 \\
\hline $\mathrm{B}$ & 3.770115 & 1.08046 & 4.149425 \\
\hline Average & 3.78 & 1.19 & 3.95 \\
\hline
\end{tabular}

\section{Conclusions}

This paper proposed a class model that targets elementary school students, and that uses gamification to help them learn about the principles of blockchain. This paper results showed that the proposed class model was able to strengthen the students' computational thinking abilities and encouraged them to spontaneously increase their learning capabilities by helping them expand their knowledge and information processing, communication, and community awareness skills.

The model motivated them to spontaneously take an interest in their learning. Additionally, the proposed class suggested a way of nurturing students' abilities such that they can analyze elements from more varied perspectives based on their understanding of the principles of blockchain. The proposed blockchain class model that using gamification is believed to offer applicabilities to the improvement of ICT education curricula[9,10]. 


\section{Acknowledgements}

This work was supported by the Ministry of Education of the Republic of Korea and the National Research Foundation of Korea(NRF-2019S1A5C2A04083374). And, this work was supported by the Korea Foundation for the Advancement of Science and Creativity(KOFAC) grant funded by the Korea government(MOE).

\section{References}

[1] Randel, Josephine M., Barbara A. Morris, C. Douglas Wetzel, and Betty V. Whitehill. (1992) "The Effectiveness Of Games For Educational Purposes: A Review Of Recent Research" Simulation \& Gaming 23 (3), 261-276.

[2] Taenam K., (2016) The effect of the lessons based gamification on academic self-efficacy : Focusing on the Korean middle school literature class, Kyunghee University, Seoul, Korea.

[3] Y. E. Oktian, I. K. Singgih and F. N. Ferdinand. (2019) Serious Game for Blockchain Education Purposes (using Proof-of-Work Consensus of Bitcoin). 2019 5th International Conference on New Media Studies (CONMEDIA), Bali, Indonesia, 177-183.

[4] Jinsu K., Namje P., Geonwoo K. and Seunghun J. (2019) CCTV Video Processing Metadata Security Scheme Using Character Order Preserving-Transformation in the Emerging Multimedia. Journal of ELECTRONICS. 8(4), 412.

[5] Livingston, Samuel A, and Clarice Stasz Stoll. (1973) Simulation Games. New York: Free Press.

[6] Donghyeok L., Namje P. (2017) Electronic identity information hiding methods using a secret sharing scheme in multimedia-centric internet of things environment. Journal of Personal and Ubiquitous Computing. 22(1), 3-10.

[7] Namje P, Namhi K. (2016) Mutual Authentication Scheme in Secure Internet of Things Technology for Comfortable Lifestyle. Journal of SENSORS. 16(1), 20.

[8] Kapp, K. M. (2012) The Gamification of Learning and Instruction: Game-based Methods and Strategies and Education. New York: Pfeiffer.

[9] Namje P., Younghoon S., Youngsik J., Soo-Bum S., Chul K. (2018) The Analysis of the Appropriateness of Information Education Curriculum Standard Model for Elementary School in Korea. Journal of Studies in Computational Intelligence. 791.

[10] Namje P., Hongxin H., Qun J. (2016) Security and privacy mechanisms for sensor middleware and application in internet of things (IoT). Journal of Distributed Sensor Networks. 12(1), 1-3. 